\title{
The National Ocean Sciences Bowl
}

Pamela Baker-Masson

Consortium for Oceanographic Research and Education - Washington, DC USA

\section{When was the last time you were blown out of the water?}

Meet the students of the National Ocean Sciences Bowl (NOSB) who will impress even the saltiest of oceanographers with their command of marine science.

The knowledgeable and competitive group of students and coaches will converge upon Miami to participate in the annual National Ocean Sciences Bowl, April 2 and 3. Inaugurated in 1998, this educa-

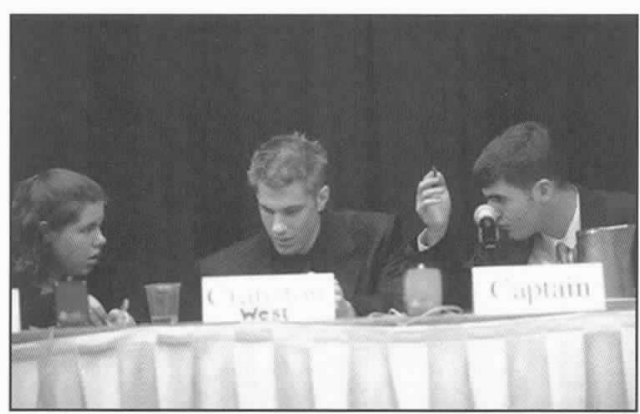

handed to both teams at the midpoint of the competition round. The questions require higher cognitive skills, often use visual aids such as charts, maps, and graphs and the students must work together to earn as many points as possible. Question difficulty increases as the competition progresses.

We annually assess the NOSB participants in order to determine tional program was developed to stimulate interest among high school students in the ocean sciences and demonstrate to the public the importance of the oceans in our daily lives.

The journey to Miami began as science teachers volunteered their time outside of the classroom to prepare the students in the subjects of biology, chemistry, geology, physics of the oceans, as well as navigation, geography and related history and literature. On an average, student teams practice several months in advance for the competition. Over 2,000 students representing 334 high schools competed in one of 19 regional competitions during the months of January and February. Universities, oceanographic institutions and aquaria served as host sites and provided the hundreds of volunteers (score keepers to science judges) required for successful regional competitions.

The past three final competitions were held in Washington, DC. By hosting the finals in conjunction with the Oceanology International Americas 2001 / The Oceanography Society conference, the participants will experience the Florida coastal locale and have the unique opportunity to meet and interact with numerous professionals and businesses in the marine industry. One important goal of this program is to expose these bright students to various marine careers so that they may better understand the opportunities that exist for them.

Teams, comprised of four students each, compete in timed matches that follow a rapid-fire, question-and-answer format. Students will be asked three types

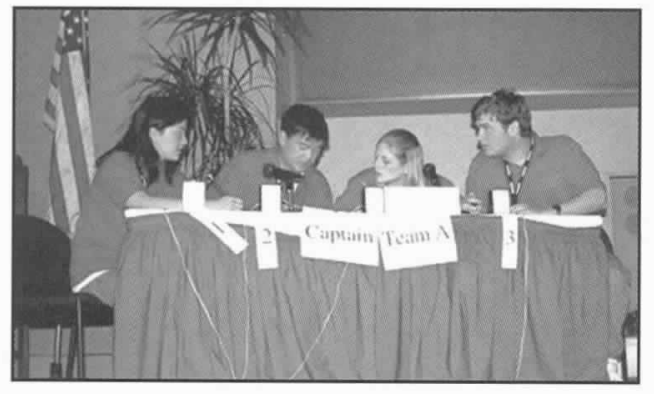
the effectiveness of our efforts. The data indicate that these students are not only improving their scientific knowledge, but they are genuinely more interested in the marine sciences as a result of their NOSB experience.

In recognition of their hard work, diligence and talents, the NOSB offers the national winning teams educational trips to ocean research destinations. Hosted by the University of Southern California's Wrigley Institute, the first place prize this year will be a science trip to Catalina Island. While on the island, participants will take part in activities with researchers and investigate the island's biological diversity both on land and in the surrounding waters. They will explore the Channel Island Marine Sanctuary and will participate on a research cruise. We have learned these types of science experiences expose students, many for the first time, to research conducted by premier marine research facilities in the country. In getting the students "wet" we hope to provide them with meaningful life experiences.

NOSB is preparing future stewards of one of Earth's most vital resources. Everyone involved with the NOSB learns something new, a discovery of why and how the oceans affect our lives, whether it be related to the econof questions, toss-up, bonus and team-challenge. The first two questions are asked orally and are in a multiple-choice or short-answer format. Unlike the oral questions, the team-challenges are written out and omy, recreation, health, weather, etc. The wellbeing of the planet will be determined in part by how all societies manage the oceans.

The Consortium for Oceanographic Research and Education (CORE) manages the NOSB. CORE is the Washington, DC-based association of 63 U.S. oceanographic research institutions, universities, laboratories and aquaria. Its mission is to promote, encourage, develop and support efforts to advance knowledge and learning in the science of oceanography and to disseminate such knowledge to 
the scientific community and to the public. The National Ocean Sciences Bowl receives financial support from six federal agencies (National Aeronautics and Space Administration, National Oceanic and Atmospheric Administration, National Science Foundation, Office of Naval Research, Oceanographer of the Navy, and the U.S. Geological Survey), Royal Caribbean International, Center for Marine Conservation, Anteon Corporation and the James D. Watkins Fund. For additional information, visit the NOSB web site at: http://www.nosb.org

\section{National Ocean Sciences Bowl ... Sample Questions}

1. Biology-Multiple Choice, Difficulty Level-Easy Question: The world's largest fish is a filter-feeder that depends on plankton as a food source. This fish is the...?
Mola mola
Blue whale
Whale shark
Megamouth shark

2. Biology-Multiple Choice, Difficulty Level-Moderate Question: Sponges belong to which of the following phyla?
coelenterata
porifera
echinodermata
cnidaria

3. Physics-Short Answer, Difficulty Level-Easy Question: What is the name given to the tides which have the smallest tidal range?

4. Physics-Multiple Choice, Difficulty Level-Moderate Question: The maximum density of seawater at the surface of the world's oceans would occur...?

$$
\begin{aligned}
& \text { at } 0^{\circ} \mathrm{C} \\
& \text { at } 4^{\circ} \mathrm{C} \\
& \text { at its freezing point } \\
& \text { after it turns to ice }
\end{aligned}
$$

5. Chemistry-Short Answer, Difficulty Level-Easy Question: What is the major anion (an-eye-on) in seawater?

6. Chemistry-Multiple Choice, Difficulty Level-Easy Question: When carbon dioxiode combines with ocean water, it produces...?

carbonate

bicarbonate

carbonic acid

calcium carbonate

7. Geology-Multiple Choice, Difficulty Level-Moderate Question: What percent of the world's fresh surface water is contained in the Great Lakes?

$$
\begin{aligned}
& 10 \% \\
& 20 \% \\
& 50 \% \\
& 66 \%
\end{aligned}
$$

8. Geography-Multiple Choice, Difficulty Level-Easy Question: At dusk, the smallest angle between the horizon and the North Star (Polaris) is 22 degrees. Your latitudinal position is...?

$$
\begin{aligned}
& 44 \text { degrees } N \\
& 78 \text { degrees } N \\
& 22 \text { degrees } N
\end{aligned}
$$$$
46 \text { degrees } N
$$

9. Technology-Multiple Choice, Difficulty Level-Easy Question: The chronometer developed by John Harrison was valuable because it made possible the accurate determination of...?
latitude
true north
inclination
longitude

10. Social Science-Multiple Choice, Difficulty LevelModerate

Question: Benjamin Franklin's nephew, Timothy

Folger, produced the first map of the...?

North Atlantic Ocean

Gulf Stream

Labrador Currents

U.S. Coastal Waters

11. Biological- short answer, Difficulty Level-Easy Question: What are the two major limiting factors controlling the vertical and horizontal distribution of the primary productivity of phytoplankton in the ocean?

12. Physical-multiple choice, Difficulty Level-Moderate Question: Precession (pre-ce-shun) of the lunar orbit is responsible for variations in tidal range which have a period of 18.6...?
days
weeks
months
years

13. Technology-multiple choice, Difficulty Level-Moderate Question: Ships move from Lake Erie to Lake Ontario by...?

The Welland Canal

the Niagara River

the St. Lawrence River

the Detroit River

14. Biological-multiple choice, Difficulty Level-Difficult Question: Which of the following is an example of parasitic symbiosis?

algal cells living within the tissue of flatworms

bioluminescent bacteria living in the body cavities of squid polychaete worms living among the gills of groupers

anemones attached to the shells of hermit crabs

Answers:

1) Whale shark, 2) porifera, 3) neap tides, 4) at its freezing point, 5) chlorine (Cr), 6) bicarbonate, 7) $20 \%, 8) 22$ degrees $\mathrm{N}, 9)$ longitude, 10) Gulf Stream, 11) Light and nutrients, 12) years, 13) The Welland Canal, 14) polychaete worms living among the gills of groupers 